ISSN 2179-345X

Licenciado sob uma Licença Creative Commons

\title{
A atividade portuária como garantidora do Princípio da Sustentabilidade
}

\author{
Port activity as a guarantor of the Sustainability Principle
}

\author{
Denise Schmitt Siqueira Garcia
}

Doutora em Direito Ambiental e Sustentabilidade pela Universidade da Espanha, professora do Programa de Pós-Graduação Stricto Sensu em Ciência Jurídica da Universidade do Vale do Itajaí (Univali), Itajaí, SC - Brasil, e-mail denisegarcia@univali.br

\section{Resumo}

Os portos, dentro da história, sempre tiveram e continuam tendo grande destaque no desenvolvimento econômico e social dos povos e, atualmente, essa importância tem cada vez mais evidência em razão da globalização. Assim, considerando a necessidade de existência de desenvolvimento econômico para que ocorra desenvolvimento social e assim proteção ambiental, ou seja, a necessidade da proteção das três dimensões do Princípio da Sustentabilidade, o presente artigo tem como objetivo principal analisar se a atividade portuária é garantidora desse princípio, verificando se ela gera desenvolvimento econômico e social. Para tanto, em um primeiro momento será feito um estudo sobre o desenvolvimento da atividade portuária e sua importância a título nacional e mundial. Na segunda parte, 
serão destacados impactos negativos e positivos que são gerados no desenvolvimento da atividade portuária. E por fim se destacará a ligação existente entre a atividade portuária e o Princípio da Sustentabilidade, ou seja, será verificado se a atividade portuária gera desenvolvimento econômico, gerando o desenvolvimento social e consequentemente a proteção ambiental. Dentro desse contexto, há que se levar em consideração que como a pobreza é uma das principais causas de depredação do ambiente, a atividade que gera desenvolvimento econômico e consequentemente desenvolvimento social deverá ser considerada como uma atividade garantidora do Princípio da Sustentabilidade.

Palavras-chave: Atividade portuária. Portos. Princípio da Sustentabilidade.

\section{Abstract}

The ports within the history always had and still have great prominence in economic and social development of people and currently this importance has increasing evidence due to globalization. Thus, considering the necessity for economic development to occur social development and environmental protection as well, in other words, the need for protection of the three dimensions of the Sustainability Principle, this article aims to analyze if the port activity is the guarantor of that principle, verifying whether it generates economic and social development. Therefore at first will be done a study about the development of port activity and its importance to national and world title. In the second part will be posted negative and positive impacts that are generated in the development of port activity and ultimately will stand the link existent between the port activity and the Sustainability Principle, ie will be checked if the port activity generates economic development, generating social development and consequently environmental protection. Within this context one must take into consideration: as poverty is one of principal causes of environmental depredation, the activity that generates economic development and consequently social development should be considered as an activity of the guarantor Sustainability Principle.

Keywords: Port activity. Ports. Sustainability Principle.

Rev. Direito Econ. Socioambiental, Curitiba, v. 3, n. 2, p. 375-399, jul./dez. 2012 


\section{Introdução}

A atividade portuária é considerada a espinha dorsal do desenvolvimento, sendo, portanto, necessária para que os países possam sobreviver no mundo globalizado que nos é imposto. É evidente que, dentro da atual conjuntura em que vivemos faz-se necessária uma preocupação latente na proteção ambiental, não sendo novidade que essa atividade é grande depredadora do ambiente. Contudo, serão destacadas no presente artigo as contribuições econômicas e sociais geradas no desenvolvimento dessa atividade, o que gera uma melhora considerável na qualidade de vida das pessoas.

Seguindo as premissas que amparam o Princípio da Sustentabilidade, há que se destacar que este possui três importantes dimensões: a ambiental, a social e a econômica. Sendo assim, a atividade portuária vem justamente de encontro com essas três dimensões, pois os portos, dentro da história, sempre tiveram e continuam tendo grande destaque no desenvolvimento econômico e social dos povos. Atualmente, essa importância tem cada vez mais evidência em razão da globalização, sendo essas dimensões, portanto, responsáveis por uma cadeia logística global.

Assim, considera-se que para o alcance do Princípio da Sustentabilidade há que se alcançar, além da proteção ambiental, também o desenvolvimento econômico e a proteção dos direitos sociais, pois a pobreza é uma das maiores degradantes do meio ambiente. Surge, assim, a importância do presente tema, que debate a importância do desenvolvimento da atividade portuária para o alcance dessas três dimensões.

\section{A importância da atividade portuária no Brasil}

Os portos sempre tiveram uma relação muito direta na história das cidades, visto que ao buscar as condições geográficas favoráveis à construção do porto, águas calmas e profundas, também se levava em consideração as condições territoriais adequadas à urbanização, mananciais 
de água potável e uma posição estratégica que possibilitasse o desenvolvimento do comércio (GITAHY, 1992).

Não há dúvida, portanto, acerca da relação de quase todas as grandes cidades brasileiras com o mar, fator que está intimamente ligado ao papel histórico de seus portos. Portas de entrada dos colonizadores e dos escravos, por um lado; e portas de saída das riquezas sobre as quais se baseavam os diferentes ciclos econômicos brasileiros (desde o pau-brasil até o café), as cidades brasileiras mantinham, entre si e com a metrópole portuguesa, uma relação de arquipélago (SILVA; COCCO, 1999, p. 9).

No Brasil, a realidade portuária é muito presente, ante a existência de 44 grande portos (pelo menos 30 considerados marinhos) e cerca de 140 terminais portuários distribuídos ao longo de $8.698 \mathrm{~km}$ de linha de costa e $12.000 \mathrm{~km}$ de extensão de hidrovias (OLIVEIRA, 2008).

O transporte aquaviário no mundo gira em torno de $90 \%$ do comércio mundial, com uma frota de aproximadamente 50.000 navios (OLIVEIRA, 2008). Esse transporte aquaviário é, portanto, uma grande fonte geradora de riquezas e, consequentemente, aquece a economia dos países envolvidos e, também, do local que possui um porto onde ocorre a maioria das negociações decorrentes desse transporte marítimo.

Uma legislação muito importante no Brasil foi a Lei n. 6.222 de 10 de junho de 1975, que autorizou o Poder Executivo a criar a Empresa de Portos do Brasil S. A., Portobrás, vinculada ao Ministério dos Transportes. Essa empresa teve como objetivo principal o de pulverizar a administração dos portos, que era considerada muito centralizadora. Contudo, a empresa passou a controlar 25 portos, dos quais 15 eram administrados por oito companhias docas e dez por ela própria. Como se percebe, a descentralização não ocorreu (COLLYER, 2008, p. 29).

Os portos na era industrial, portanto, eram administrados pelo Estado por meio de órgãos como a Portobrás. Assim, eram chamados a desempenhar, alternativamente, um papel relevante no desenho da matriz territorial de integração econômica e política. Dessa forma, o Estado acabava impondo sua lógica de desenvolvimento aos poderes locais (COLLYER, 2008, p. 29). 
O modelo de gestão das infraestruturas e de organização dos serviços portuários correspondentes a esse regime de produção era fortemente determinado por essa pauta de atuação. Ele tinha, em termos gerais, a seguinte configuração:

a) Gestão e administração centralizada dos portos, através de um órgão governamental 'autônomo' com relação às instituições locais;

b) participação privada em operações específicas de movimentação de cargas, principalmente minérios e outros granéis líquidos e sólidos;

c) monopólio estatal na movimentação de cargas de terceiros, fundamentalmente cargas gerais e conteinerizadas;

d) acordos coletivos de trabalho e financiamento público das infra-estruturas e dos equipamentos de grande porte (COLLYER, 2008, p. 29).

Diante disso, os portos mantinham um perfil altamente setorizado, ou seja, segmentado e direcionado à movimentação de tipos específicos de carga, sem se mostrarem muito flexíveis às variações da natureza do produto, às modificações da tecnologia dos transportes ou às alternativas do mercado (COLLYER, 2008, p. 16).

Nas décadas de 1970 e 1980, iniciaram-se os debates sobre a problemática dos portos, principalmente a ociosidade e os altos custos. Segundo Collyer (2008, p. 32):

por experiência profissional podemos afirmar que os portos brasileiros tinham o odor de mofo e de burocracia; pareciam ambientes inóspitos, com muros sujos que os isolavam das cidades e desencorajavam qualquer tentativa de proximidade por parte da população, bem diferente do que ocorria com os terminais europeus.

A Lei n. 8.029, de 12 de abril de 1990, surgiu com a ideia de descentralização, extinguindo a Portobrás. A política portuária brasileira passou, então, à competência da Secretaria de Transportes Aquaviários 
(STA) e ao Departamento Nacional de Transportes Aquaviários (DNTA), subordinado ao Ministério dos Transportes (COLLYER, 2008, p. 29).

Assim, para implementação dessa nova fase portuária nas últimas décadas do século XX, de modo a atender a uma nova demanda da logística globalizada, foi necessário um processo de modernização dos portos no Brasil. Esse fato teve por consequência impacto socioeconômico negativo para as cidades, com uma relação significativa da mão de obra empregada nas atividades portuárias. $\mathrm{O}$ fato gerador dessas mudanças foi o advento da intermodalidade (integração da circulação de mercadorias entre os principais portos do mundo), que, para viabilidade, depende da padronização dos meios de transporte de carga marítimo-terrestre, por meio da utilização de cargas e containers. Por consequência desse novo perfil logístico, ocorreram várias mudanças na ocupação do solo e do zoneamento das áreas do porto, buscando-se assim a otimização dos espaços e novas áreas para construção de terminais de carga, tornando-se a atividade portuária intensiva em capital e excludente de mão de obra (MORAES, 2007, p. 332).

Com a promulgação da Lei n. 8.630/1993, chamada de Lei de Modernização dos Portos, permitiu-se um novo modelo de privatização de serviços portuários, o comando único das equipes de trabalho e a operação de cargas de terceiros em terminais privados.

Com todas essas mudanças exigidas pela lei e pela necessidade de aprimoramento da atividade portuária, os portos estatais passaram a integrar um conjunto de unidades autônomas, vinculadas ao Ministério dos Transportes e reguladas pela Agência Nacional dos transportes Aquaviários (ANTAQ). Nascem, assim, as autoridades portuárias (Companhia das Docas) e os Conselhos da Autoridade Portuária (CAP), formado por membros dos Poderes Executivos - nas esferas federal, estadual e municipal -, representantes das diversas empresas privadas, e trabalhadores (MORAES, 2007, p. 333). 
Percebe-se então que essa lei vai de encontro ao que está previsto no artigo 22, inciso $\mathrm{X}^{1}$, e artigo 21, inciso $\mathrm{XII}^{2}$, da Constituição da República Federativa do Brasil. Eis que essa lei incorporou pretensões privatizantes, em uma postura contrária até mesmo a toda a tendência universal sobre a matéria. Todos os Estados têm ciência e consciência de que a área portuária é muito mais que um lugar de embarque e desembarque, de carga e descarga, porque é fronteira nacional, um lugar extraordinariamente sensível à defesa do nosso território. Trata-se de uma área, enfim, onde se desenvolvem as atividades de controles diversos, de migração, vigilância sanitária, inspeção e classificação de produtos, fiscalização aduaneira, alfândega e arrecadação de tributos, policiamento de repressão ao contrabando e outras tantas mais ${ }^{3}$.

De todo o exposto, percebe-se que os portos foram e são de suma importância para o desenvolvimento do país. Eles se fizeram presentes aqui desde a época do descobrimento até os dias atuais, sendo, portanto, responsáveis pelo desenvolvimento econômico e social do país.

1 Artigo 22 Compete privativamente à União legislar sobre: Inciso X - regime dos portos, navegação lacustre, fluvial, marítima e aeroespacial.

2 Artigo 21 Compete à união:

Inciso XII - explorar, diretamente ou mediante autorização, concessão ou permissão:

d) os serviços de transporte ferroviário e aquaviário entre os portos brasileiros e fronteiras nacionais, ou que transponham os limites de Estados ou Território; f) os portos marítimos, fluviais e lacustres.

3 Cabe aqui ainda destacar que o constitucionalista José Afonso da Silva interpôs, em 26 de agosto de 1993, uma Ação Direta de Inconstitucionalidade (ADI 929-0) representando a Fenccovib, a Federação Nacional de Estivadores, a Federação do Portuários e os partidos políticos PSB, PCB , PDT e posteriormente o PT. Em 1997 houve a exclusão do polo ativo das federações, permanecendo somente os partidos políticos. Desde 1 de junho de 1998, os autos encontram-se conclusos ao relator e ainda aguardam julgamento (COLLYER, W. O. Lei dos portos: o conselho de autoridade portuária e a busca da eficiência. São Paulo: Lex, 2008. p. 52). 


\section{Dos impactos negativos e positivos gerados no desenvolvimento da atividade portuária}

É evidente que não se pode negar que a atividade portuária gera impactos negativos diretos ao meio ambiente, principalmente no local onde o porto se instala para realização de suas atividades. Contudo, deve-se considerar em contrapartida que há a geração de impactos econômicos, que, por conseguinte, aprimoram o status social da população, ou seja, aumenta a qualidade de vida das pessoas com a geração de riquezas trazidas, o que ocasiona a diminuição da pobreza. Neste artigo científico, destaca-se que serão levados em consideração somente alguns impactos negativos e positivos, não se podendo esgotar o tema.

Um dos impactos negativos que se destaca é a água de lastro. Essa água é usada quando os navios não estão completamente carregados e dependem do uso de lastro para manter a integridade estrutural. Até 1880, utilizaram-se de pedras ou areia para lastrear as embarcações. A partir daí, generalizou-se o uso da água e, até hoje, não se encontrou melhor substituto (COLLYER, 2007, p. 146-147).

Conceitua-se água de lastro como: "a água com suas partículas suspensas levadas a bordo de um navio nos seus tanques de lastro, para controle do trim, banda, calado, estabilidade ou tensões do navio" (OLIVEIRA, 2008).

A liberação posterior dessas águas de lastro que estão nos navios ocasiona invasões biológicas de vírus, bactérias, plantas, pequenos invertebrados, ovos, cistos e larvas de animais. Essa contaminação gera impactos ecológicos, econômicos e na saúde da população.

Os registros de bioinvasão por meio da água espalham-se pelo mundo inteiro. Existem algumas invasões de espécies alienígenas que são históricas, tais como: mexilhão-zebra nos EUA, dinoflagelados na Austrália, água-viva carnívora nos EUA, bem como a invasão do mexilhão dourado no Brasil (ÁGUA DE LASTRO BRASIL, 2009, p. 1-2).

Outra forma de contaminação da água em razão da invasão de micro-organismos e outros animais é a incrustação do casco dos navios. 
Essa incrustação é uma das mais agressivas formas de transferências de espécies exóticas. Além dos cascos, outros pontos existem que facilitam essa transferência de organismos, como, por exemplo, tubulações, correntes, âncoras e hélices.

Assim, para um melhor gerenciamento dessas águas de lastro há que se observar as seguintes recomendações: a) adoção de critérios e diretrizes nacionais para o licenciamento ambiental de portos; b) estruturação dos setores de meio ambiente dos portos (recursos humanos e materiais); c) estabelecimento de um sistema nacional de informações ambientais portuárias, publicamente acessível, com atualização constante, contemplando aspectos do gerenciamento da água de lastro (banco de dados nacional das espécies invasoras, redes de informações internacionais); d) adoção de políticas específicas para a melhoria das condições de saneamento dos ambientes portuários (OLIVEIRA, 2008).

Há que se destacar, também, a realização de uma Convenção Internacional chamada de Marpol 73/78, a qual foi assinada no dia 17 de fevereiro 1973 e modificada pelo Protocolo de 1978. Marpol 73/78 é a mais importante convenção ambiental marítima, foi projetada para minimizar a poluição dos mares e tem como objetivo: preservar o ambiente marinho pela eliminação completa de poluição por óleo e outras substâncias prejudiciais, bem como, minimizar as consequências nefastas de descargas acidentais de tais substâncias.

No Brasil, existe uma norma da autoridade marítima para o gerenciamento da água de lastro de navios - NORMAM 20 (desde outubro de 2005) -, a qual prevê práticas a serem cumpridas por todos os navios equipados com tanques/porões de água de lastro que entrem ou naveguem em águas jurisdicionais brasileiras.

No Brasil também existe a Lei n. 9.966/2000, que dispõe sobre a prevenção, o controle e a fiscalização da poluição causada por lançamento de óleo e outras substâncias nocivas ou perigosas em águas sob jurisdição nacional e dá outras providências. Também a Lei n. 10.233/2001, que dispõe sobre a reestruturação dos transportes aquaviário e terrestre, cria o Conselho Nacional de Integração de Políticas de Transporte, 
a Agência Nacional de Transportes Terrestres, a Agência Nacional de Transportes Aquaviários e o Departamento Nacional de Infra-estrutura de Transportes, e dá outras providências.

Outro impacto ambiental que merece destaque com o desenvolvimento da atividade portuária é a geração de resíduos. É comum nas áreas portuárias a existência de resíduos dos mais diversos tipos, como sucatas, entulhos, madeiras, material orgânico, cargas mal acondicionadas, material de escritório, material plástico, pilhas e baterias, lâmpadas, além do acúmulo de grãos e resíduos de cargas nos pátios em razão do acondicionamento e da limpeza inadequados, durante carga e descarga para transporte ou armazenamento temporário. Vários, portanto, são os resíduos encontrados nos portos. Resíduos esses que são produzidos pelos arrendatários e permissionários como também gerado pelos tripulantes.

Um dos fatores que deve ser observado para o bom gerenciamento desses resíduos encontrados na área portuária é a educação ambiental das pessoas envolvidas. Somente com ela o homem "descobre que pode mudar a realidade, que ele é capaz de decidir, que tem responsabilidade social e política, pois só a educação permite aos homens exercer sua cidadania, participando na solução dos problemas ambientais, na busca de uma melhor qualidade de vida" (MONTEIRO Jr.; VENDRAMETTO, 2009 , p. 3). Para tanto, em razão da grande incidência de resíduos advindos da atividade portuária, todos os porto devem ter um plano de gerenciamento de resíduos sólidos.

Existe uma Resolução n. 05, de 5 de agosto de 1993, elaborada pelo Conselho Nacional do Meio Ambiente (Conama), que define as normas mínimas para tratamento de resíduos sólidos oriundos de serviços de saúde, portos e aeroportos, bem como a necessidade de estender tais exigências aos terminais ferroviários e rodoviários.

O terceiro impacto negativo destacado é a poluição atmosférica gerada pela atividade portuária. Os fatores que causam a poluição atmosférica nos portos são vários: 
a) tráfego de carros e caminhões, sendo a maioria movidos a diesel;

b) tráfego de navios comerciais;

c) equipamentos de manejo de cargas (empilhadeiras);

d) manejo e armazenamento de produtos químicos;

e) combustível de navios, caminhões, trens e de equipamentos de manejo de cargas;

f) descargas líquidas dos navios;

g) pintura de navios;

h) rachadura de navios;

i) manutenção e reparo de rodas, assoalho, combustível, veículos e equipamentos;

j) canais de drenagem;

k) poluição do ar de operações portuárias e atividades de construção, incluindo smog e poluição por partículas tóxicas;

1) perda ou degradação de áreas marinhas, destruição de pescarias;

m) diminuição de local de habitat de espécies;

n) contaminação por efluentes;

o) severos congestionamentos no tráfego;

p) poluição sonora e atmosférica;

q) contaminação do solo e água de vazamentos de tanques de armazenamento e oleodutos;

r) liberação na atmosfera de poluentes químicos;

s) geração de sólidos e efluentes perigosos e assoreamento de solos e erosão (VIEIRA, 2007, p. 20).

Percebe-se que os portos são locais de altos índices de poluição do ar, poluição essa que afeta a saúde das pessoas que vivem próximas, bem como contribuem sobremaneira com os problemas de poluição do ar regional.

É preciso que ocorra uma mudança rápida nesse setor e, para tanto, se faz necessária uma conscientização das empresas e seus funcionários, um investimento grande em tecnologias que busquem a diminuição dessas emissões contaminadoras e, finalmente, a realização de políticas públicas com a finalidade de diminuição desses agentes contaminadores. 
Outro impacto negativo gerado é o tráfego ocasionado pelo transporte terrestre nos portos. Muito embora seja uma atividade secundária, eis que a principal é o transporte de navios, gera grandes transtornos nos entornos das cidades onde esses portos estão situados. Esses congestionamentos de veículos ocorrem principalmente nas épocas de safras dos produtos, aumentando o número de acidentes e, consequentemente, os custos logísticos do país, o que reduz a competitividade de nossos produtos no mercado internacional (PEREIRA; MAIA; PEREIRA, 2011, p. 1).

A principal causa desses congestionamentos, na verdade, é a falta de capacidade de armazenagem dos portos, no período de pico, além da falta de planejamento de áreas. Um problema adicional é a excessiva especialização dos terminais, que acabam por ficar com falta de capacidade em alguns períodos e ociosos em outros (PEREIRA; MAIA; PEREIRA, 2011, p. 4).

Para tanto, é preciso criar corredores especiais de acesso aos portos ou então ampliar a capacidade viária nas proximidades para que a concorrência do transporte de cargas com o tráfego urbano não cause problemas para ambos, como acontece na maioria dos portos na atualidade (PRADO, 2009).

Outra saída seria criar pátios reguladores (ou de triagem) de caminhões para atendimento ao porto. Eles teriam como objetivo ordenar a chegada dos veículos à área portuária, funcionando como um "pulmão" para os terminais de produtos a serem embarcados nos navios. Teriam também a função de administrar o fluxo de veículos que se dirigem ao porto, de forma a proporcionar uma descarga contínua e racional, sem que sejam provocados impactos negativos na sua área de entorno e transtornos à comunidade local (PEREIRA; MAIA; PEREIRA, 2011, p. 1).

De tudo que foi dito, percebe-se que o tráfego terrestre nos portos é um problema que não pode ser desconsiderado. Contudo, várias possibilidades de melhoras foram aqui apresentadas e podem dar melhores condições para as pessoas que se veem envolvidas nesse problema. Deve ser considerado que nem todos os impactos gerados pelo desenvolvimento 
da atividade portuária são negativos, existem também os impactos positivos, os quais serão agora tratados.

Para tanto, primeiro há de se ter em mente que vivemos na era da globalização, sendo esta vista como uma transformação política, cultural, econômica e social considerada numa visão mundial. Dessa forma, deve ser considerado que os portos são um dos grandes responsáveis pela efetividade da globalização, principalmente econômica, pois geram abertura comercial, aumentando importações e exportações e impulsionando o crescimento econômico do país.

O impacto positivo a ser destacado é justamente a garantia da globalização. Como dito alhures, os portos proporcionam a interligação entre os países, aumentando as exportações e importações entre eles. Isso ocorre principalmente em virtude do baixo custo dos transportes marítimos garantindo essa integração e permitindo a união entre os centros de produção, de montagem e de distribuição das grandes empresas multinacionais.

O segundo impacto econômico ocasionado pelos portos em áreas urbanas, e um dos mais importantes, é a geração de empregos, como se pode perceber nas comprovações a seguir.

Vários são os empregos gerados pela atividade portuária, como, por exemplo, as funções desenvolvidas no âmbito portuário. Dentre elas, temos a função de operador portuário, o trabalhador portuário avulso, os estivadores, o conferente de carga, o responsável pelo conserto de carga, a função de vigilância de embarcação, bloco e capatazia e ainda os empregos que são gerados para composição dos órgãos de gerência, como o Grupo Executivo de Modernização dos Portos (Gempo) e o Órgão Gestor de Mão de Obra de Trabalhador Avulso (OGMO). Comprova-se, portanto, que são vários os empregos e funções proporcionados nesse setor.

Além dessas funções diretas ainda existem as administrativas, que precisam ser desenvolvidas dentro do porto. Temos também os biólogos, engenheiros ambientais, operadores de máquinas, caminhoneiros, despachantes aduaneiros, empresas de logísticas, dentre outras funções.

Sendo assim, os portos são portas de uma grande gama de outros serviços, além de movimentação de carga, temos também a transferência 
de passageiros, pesca, lazer e atividades recreativas. Eles também podem acomodar várias instalações industriais e, portanto, funcionam como imã para comércio e indústria, e como fonte geradora de emprego (EUROPEAN SEA PORTS ORGANISATION, 2001, p. 12).

O terceiro benefício que se destaca na atividade portuária é a possibilidade do desenvolvimento da atividade turística de cruzeiros. Nesse caso, há que se considerar os benefícios ocasionados na cidade onde esse porto se localiza, como, por exemplo: movimentação nos hotéis, restaurantes, lojas de prestação de serviços aos passageiros, divulgação da cidade, empregos para as pessoas que trabalham nos navios, dentre outros.

"No Brasil várias regiões têm a atividade turística inserida em seu conjunto macroeconômico, o que incrementa seu orçamento mensal e se traduz em melhoria da qualidade de vida para comunidade" (EUROPEAN SEA PORTS ORGANISATION, 2011, p. 12). Percebe-se, portanto, que o turismo é fonte geradora de grandes movimentações econômicas, de empregos, de renda e de receitas públicas, proporcionando desenvolvimento econômico e social, principalmente para a população que vive às margens do município.

Outro impacto é o de lucros pessoais, pois uma vez que o porto proporciona empregos os trabalhadores envolvidos na atividade portuária desenvolvem melhores condições de renda, e consequentemente podem "aquecer" a economia de outros setores da sociedade. Há que se considerar que esses gastos são na grande maioria, centralizados e regionalizados, melhorando a economia local como um todo, pois as empresas dependentes desse consumo também se desenvolvem.

Destaca-se aqui um ponto muito importante, que é a certeza de o aumento nas condições financeiras dessas pessoas trazer a proteção de seus direitos sociais, dentre eles, trabalho, lazer, segurança, previdência social, saúde, moradia, alimentação, educação, assistência aos desamparados, proporcionando a todos uma vida digna.

O impacto fiscal também é importante porque a atividade portuária, principalmente em razão do comércio exterior realizado nesse setor, gera a necessidade de pagamento de impostos aos governos Federal, 
Estadual e Municipal. Esses impostos, principalmente os estaduais e os municipais, são revertidos, na grande maioria, para a própria cidade onde o porto está instalado.

Por fim, ainda destaca-se que a existência de um porto na cidade também possibilita a manutenção de marinas, sendo estas também geradoras de negócios, de empregos e, portanto, de aquecimento da economia local, dando mais condições para os que ali vivem.

O porto passa a ser o agente necessário para o alcance de um nível de vida digno para as pessoas que vivem na cidade em que ele está instalado. Ele é fonte geradora de riqueza e, consequentemente, de alcance e manutenção dos direitos sociais dessas pessoas.

Fica clara a importância econômica e social dos portos, que vai muito além do seu volume de negócios diretos. Em uma economia como a que se vive, onde é imperativo exportar, torna-se mandatário ter um sistema portuário coerente, com alta produtividade e muito competitivo.

\section{Análise acerca do Princípio da Sustentabilidade e sua relação com os portos}

O termo sustentabilidade evidentemente comporta conotações diversas. Ele decorre do conceito de sustentação, o qual, por sua vez, é aparentado à manutenção, conservação, permanência, continuidade e assim por diante. Sustentação e manutenção, por outro lado, têm como cognatos sustento e mantença, expressões mais ligadas à ideia de prover, ou seja, aportar recursos ou dar condições para que alguém ou determinada entidade possa sobreviver ou desempenhar sua atividade por algum tempo, como requisito de permanência (NUSDEO, 2009, p. 145).

Faz-se necessário, também, colacionar a diferença entre crescimento e desenvolvimento nas palavras de Fábio Nusdeo (2009, p. 147):

por enquanto, basta guardar a distinção acima traçada entre crescimento e desenvolvimento: o primeiro caracterizado por uma maior 
geração de bens e serviços sem alterações estruturais no processo econômico e, portanto, sem a criação de condições que o tornem sustentável no tempo; o segundo, um processo autossustentado de mudanças qualitativas no funcionamento do sistema econômico aptas a assegurar a sua continuidade ao longo do tempo.

Há que se pensar na necessidade de alcance de um desenvolvimento sustentável e não de um crescimento, pois só assim será possível um processo autossustentável, sem agressões ambientais relevantes e, consequentemente, com uma qualidade de vida mínima para a sociedade.

Sustentabilidade, portanto, pode ser vista como um Princípio do Direito Ambiental que tem como objetivo alcançar as dimensões ambiental, econômica, social e política, aludindo instintivamente a um modo de atuação social que independe do modelo econômico que assuma, tendo como finalidade a permanência da espécie humana no planeta em condições dignas e justas.

Resumindo, poder-se-ia falar que esse Direito pode ser entendido como um conjunto de instrumentos "preventivos", ferramentas de que se deve lançar mão para conformar, constituir, estruturar políticas, que teriam como cerne práticas econômicas, científicas, educacionais, conservacionistas, voltadas à realização do bem-estar generalizado de toda a sociedade.

Assim, políticas que reencontrem uma compatibilização da atividade econômica, como o aumento das potencialidades do homem e do meio natural, sem exauri-las; apoiadas por normas de incentivo à pesquisa científica de proteção dos recursos naturais e de garantia de uma qualidade ambiental são expressões do direito do desenvolvimento sustentável - outra forma de compreender o Direito Ambiental (DERANI, 2008, p. 156).

A construção do desenvolvimento sustentável se consolida a partir dos anos 1970, com a primeira grande conferência internacional sobre o tema realizada em Estocolmo no ano de 1972. Nessa conferência já havia uma dialética complexa entre a pobreza, a riqueza e a destruição da natureza.

Rev. Direito Econ. Socioambiental, Curitiba, v. 3, n. 2, p. 375-399, jul./dez. 2012 
Mais tarde, o assunto foi tratado de forma mais consistente na conferência que se realizou no Rio de Janeiro em 1992. Tal documento dava um tom muito mais consistente quanto à necessidade de união entre o desenvolvimento e o meio ambiente.

Não restam dúvidas de que essas duas convenções foram alavancadoras no sentido de despertar nos órgãos governamentais e na população a necessidade e a possibilidade de interligação entre a proteção ambiental e o desenvolvimento econômico. É evidente que ninguém gostaria de retroceder no que já alcançou no campo econômico, como, por exemplo, o padrão de vida, porém para o alcance desse padrão, há que se pensar na proteção ambiental, unindo-se essas duas vertentes.

Não restam dúvidas que resta superada a noção romântica de que a natureza é um intocável santuário. O Brasil - assim como outros países menos desenvolvidos - precisa gerar riquezas e enfrentar os desafios da mudança social, cujos símbolos mais evidentes são a taxa de crescimento da população e a consolidação de uma pobreza estrutural. Há brasileiros vivendo em situação de miséria extrema; urge melhorar suas vidas, dando-lhes condições mais dignas.

Nossa ação concreta, porém, não pode ser feita sobre bases de "crescimento a qualquer preço". O meio ambiente, que é patrimônio não só da geração atual, mas também das gerações futuras, precisa ser considerado nas suas dimensões de espaço e tempo, em sucessivos 'aqui e agora'. Ou seja, é preciso crescer, sim, mas de maneira planejada e sustentável, com vistas a assegurar a compatibilização do desenvolvimento econômico-social com a proteção da qualidade ambiental em todo instante e em toda parte. Isso é condição para que o progresso se concretize em função de todos os homens e não à custa do mundo natural e da própria humanidade, que, com ele, está ameaçada pelos interesses de uma minoria ávida por lucros e benefícios (MILARÉ, 2007, p. 63).

É importante sempre lembrar que a pobreza, o subconsumo forçado, é algo intolerável que deve ser eliminado como uma das tarefas mais urgentes da humanidade. A pobreza, a exclusão social e o desemprego devem ser tratados como problemas planetários, tanto quanto a chuva 
ácida, o efeito estufa, a depleção da camada de ozônio e o entulho espacial que se acumula ano a ano. Questões essas que estão no cerne das novas concepções de sustentabilidade (BARBIERI, 2000, p. 32).

Sendo assim, o desenvolvimento sustentável não é um princípio específico, mas um conjunto de regras implícitas que passaram a fazer parte da preocupação da população, consciente da necessidade de manutenção da vida na Terra.

Percebe-se de todo o exposto até o momento, que desenvolvimento e meio ambiente estão inevitavelmente interligados. O desenvolvimento não se mantém se a base de recursos ambientais se deteriora; o meio ambiente não pode ser protegido se o crescimento não leva em conta as consequências da destruição ambiental. Sendo assim, esses problemas não podem ser tratados separadamente por instituições e políticas fragmentadas. Eles fazem parte de um sistema complexo de causa e efeito (BARBIERI, 2000, p. 40).

Como bem salientado no decorrer da pesquisa, a pobreza é a grande causadora da degradação ambiental no planeta Terra, pois quem passa fome e, consequentemente, não possui condições mínimas de sobrevivência não tem condições de pensar razoavelmente sobre a proteção ambiental.

Na Conferência Mundial sobre o Meio Ambiente ocorrida na África do Sul, em Johannesburgo, onde realmente houve a integração entre os três grandes componentes da sustentabilidade - o econômico, o social e o ambiental -, houve o aumento das discussões acerca da necessidade da proteção da dimensão social às pessoas necessitadas. Com isso, haveria uma diminuição da pobreza e, consequentemente, o aumento da proteção ambiental.

Assim, há algum tempo o combate à pobreza é reconhecido como o maior desafio da sociedade internacional. O Programa das Nações Unidas para o desenvolvimento (PNUD), que é um órgão ligado à 
Organização das Nações Unidas (ONU), traz como seu principal objetivo o combate à pobreza ${ }^{4}$.

Também se vislumbra o suporte teórico dessa afirmação nas palavras de Paulo de Bessa Antunes (2006), que diz que para haver proteção ambiental é necessária a melhoria nos níveis de renda da população, bem como uma melhoria na distribuição dessa renda. Tal autor relata ainda que há uma relação perversa entre condições ambientais e pobreza. Assim, a melhoria da proteção ambiental depende de uma adequada distribuição de renda.

Percebe-se que existe a necessidade do atendimento dos direitos sociais das pessoas para que possa ser garantido o Princípio Constitucional da Dignidade Humana e, assim, possa-se pensar em proteção ambiental, pois como dito alhures quem passa fome não tem condições de pensar em proteção ambiental.

Portanto, o enfrentamento dos problemas ambientais e a opção por um desenvolvimento sustentável passam, necessariamente, pela correção do quadro alarmante de desigualdade social e da falta de acesso da população pobre aos seus direitos sociais básicos, o que, diga-se de passagem, também é causa potencializadora da degradação ambiental. O projeto da modernidade está em curso, os direitos sociais foram deixados no meio do caminho, além de ter sido agregado um novo desafio existencial ao projeto: a proteção do ambiente (FENSTERSEIFER, 2008, p. 105).

Vislumbra-se, portanto, a necessidade de melhoria das condições de vida das pessoas com o alcance e a manutenção dos direitos sociais a essas pessoas. Considera-se, que o trabalho é um dos grandes responsáveis pela melhoria das condições de vida das pessoas e por amenizar a pobreza.

Como já comentado anteriormente na pesquisa, os portos possibilitam o desenvolvimento do comércio exterior, e isso faz com que

4 Foram apresentados anteriormente na pesquisa os objetivos do milênio, que foram elaborados pelo PNUD, todos tratados com o objetivo central de diminuição da pobreza como forma de preservação ambiental. 
ocorra um aumento na captação de capitais, com o aumento das exportações e maior facilidade nas importações. Aqui se apresenta uma relação muito importante entre a proteção ambiental e os portos, em razão da diminuição da pobreza que essa fonte geradora de riqueza vai trazer para o local onde for instalada.

Considera-se que, em regra, a miséria e a pobreza (como projeções da falta de acesso aos direitos sociais básicos, como saúde, saneamento básico, educação, moradia, alimentação, renda mínima, etc.) caminham juntas com a degradação e a poluição ambiental, expondo a vida das populações de baixa renda e violando sob duas vias distintas a sua dignidade. Aí está a importância de uma tutela compartilhada dos direitos sociais e dos direitos ecológicos, em vista de criar um núcleo mínimo para a qualidade de vida, aquém do qual poderá haver vida, mas esta não será digna de ser vivida (FENSTERSEIFER, 2008, p. 277).

Os portos vêm atender a uma dessas vertentes, que é a garantia de emprego, de desenvolvimento programado em uma cidade, dando condições de vida melhor e mais digna às pessoas e, consequentemente, um amadurecimento na proteção ambiental.

Outros fatores também devem ser observados para manutenção de uma atividade que gera impacto ambiental, como ocorre com a atividade portuária, como, por exemplo, o crescimento da população, a diminuição da desnutrição e a diminuição da pobreza.

Todas essas ideias amparam a tese sustentada, pois considerando os portos como causadores de impactos ambientais, deve-se fazer uma ponderação acerca de suas contribuições para verificação da possibilidade de compensação desses danos em virtude da implementação das outras dimensões garantidas por essa atividade, como a dimensão econômica e a social. A atividade portuária como geradora de riqueza proporciona a diminuição da pobreza, uma das maiores causadoras de danos ambientais ao planeta.

Fica claro que o desenvolvimento econômico é necessário para que ocorra proteção ambiental e, considerando que a pobreza é uma das causas mais degradantes desse meio, o aumento da riqueza faz gerar essa proteção. 
Destaca-se, portanto, como contribuição gerada pela instalação dos portos em uma cidade, esse "aquecimento" na economia que ele traz em vários setores da sociedade, proporcionando melhoria de vida. Essa melhoria gerada pelo aumento do potencial econômico da população liga-se diretamente à proteção dos direitos sociais dessas pessoas, garantindo-lhes o mínimo existencial, que seria o mínimo necessário para a manutenção dos direitos fundamentais sociais. Esse mínimo existencial corresponde ao "núcleo duro" dos Direitos fundamentais, não podendo ser alterados ou retirados sob pena de violação do Princípio da Dignidade Humana.

\section{Considerações finais}

A atividade portuária é essencial para o desenvolvimento econômico e social, trazendo relevantes benefícios à população. Ela é a grande responsável pela interligação entre os países, aumentando as exportações e importações entre eles e, consequentemente, garantindo a globalização.

A atividade portuária gera grandes impactos ambientais, porém também gera impactos econômicos, contribuindo com a diminuição da pobreza e, consequentemente, com a melhoria na qualidade de vida da população, fazendo com que tenham condições de proteger o ambiente.

A pobreza, e consequentemente a ausência de direitos sociais, é uma das principais causas da degradação ambiental, conforme vem sendo discutido em todas as conferências mundiais sobre o meio ambiente ocorridas até o momento.

O Princípio da Sustentabilidade deve ser analisado em três dimensões: a econômica, a social e a ambiental, existindo duas precondições para sua existência. A primeira é a capacidade natural de suporte, que seriam os recursos naturais existentes; e a segunda, a capacidade de sustentação, que seriam as atividades sociais, políticas e econômicas geradas pela própria sociedade em seu próprio benefício.

Portanto, como a atividade portuária traz relevantes benefícios à população, pois é fonte de riqueza, o que contribui com a diminuição 
da pobreza e, consequentemente, com a melhoria na qualidade de vida dessa população, fazendo com que tenham condições de entendimento sobre a necessidade de proteção ambiental, constata-se que existe compensação dos impactos ambientais com os impactos econômicos gerados por essa atividade, havendo, dessa forma, a garantia do Princípio da Sustentabilidade em suas três dimensões.

\section{Referências}

ÁGUA DE LASTRO BRASIL. FAQ. 2009. Disponível em: <http://aguadelastrobrasil.org.br/faqs. html>. Acesso em: 24 jun. 2011.

ANTUNES, P. de B. Direito ambiental. Rio de Janeiro: Lumen Juris, 2006.

BARBIERI, J. C. Desenvolvimento e meio ambiente: as estratégias de mudanças da Agenda 21. 3. ed. Petrópolis: Vozes, 2000.

BRASIL. Senado Federal. Lei n. 6.222, de 10 de julho de 1975. Autoriza o Poder Executivo a constituir a empresa pública denominada Empresa de Portos do Brasil S.A. Portobrás, dispõe sobre a extinção do Departamento Nacional de Portos e Vias Navegáveis - DNPVN, e dá outras providências. Diário Oficial [da] República Federativa do Brasil, Poder Legislativo, Brasília, DF, 10 jul. 1975. Disponível em: <http://www6.senado.gov.br/legislacao/ListaTextoIntegral. action?id =190229\&norma=205225 . Acesso em: 23 dez. 2011.

BRASIL. Presidência da República. Lei n. 8.029, de 12 de abril de 1990. Dispõe sobre a extinção e dissolução de entidades da administração Pública Federal, e dá outras providências. Diário Oficial [da] República Federativa do Brasil, Poder Legislativo, Brasília, DF, 12 abr. 1990. Disponível em: <http://www.planalto.gov.br/ccivil_03/leis/L8029cons.htm>. Acesso em: 23 dez. 2011. 
BRASIL. Presidência da República. Lei n. 8.630, de 25 de fevereiro de 1993. Dispõe sobre o regime jurídico da exploração dos portos organizados e das instalações portuárias e dá outras providências. (Lei dos Portos). Diário Oficial [da] República Federativa do Brasil, Poder Legislativo, Brasília, DF, 25 fev. 1993. Disponível em: 〈http://www.planalto.gov.br/ccivil_03/leis/18630.htm>. Acesso em: 23 dez. 2011.

BRASIL. Presidência da República. Lei n. 10.233, de 5 de junho de 2001. Dispõe sobre a reestruturação dos transportes aquaviário e terrestre, cria o Conselho Nacional de Integração de Políticas de Transporte, a Agência Nacional de Transportes Terrestres, a Agência Nacional de Transportes Aquaviários e o Departamento Nacional de Infra-Estrutura de Transportes, e dá outras providências. Diário Oficial [da] República Federativa do Brasil, Poder Legislativo, Brasília, DF, 5 jun. 2001. Disponível em: <http://www.planalto.gov.br/ccivil_03/ leis/LEIS_2001/L10233.htm>. Acesso em: 23 dez. 2011.

BRASIL. Presidência da República. Lei n. 9.966, de 28 de abril de 2002. Dispõe sobre a prevenção, o controle e a fiscalização da poluição causada por lançamento de óleo e outras substâncias nocivas ou perigosas em águas sob jurisdição nacional e dá outras providências. Diário Oficial [da] República Federativa do Brasil, Poder Legislativo, Brasília, DF, 28 abr. 2002. Disponível em: <http:// www.planalto.gov.br/ccivil_03/leis/L9966.htm>. Acesso em: 23 dez. 2011.

BRASIL. Presidência da República. Resolução CONAMA n. 5, de 5 de agosto de 1993. Dispõe sobre o gerenciamento de resíduos sólidos gerados nos portos, aeroportos, terminais ferroviários e rodoviários e estabelecimentos prestadores de serviços de saúde. (Revogadas as disposições que tratam de resíduos sólidos oriundos de serviços de saúde pela Resolução n. 358/05). Diário Oficial [da] República Federativa do Brasil, Brasília, DF, n. 116, seção 1, p. 12996-12998, 31 ago. 1993. Disponível em: <http://www.mp.go.gov.br/portalweb/hp/9/docs/ rsulegis_03.pdf >. Acesso em: 23 dez. 2011.

COLLYER, W. Água de lastro, bioinvasão e resposta internacional. Revista Jurídica, Brasília, v. 9, n. 84, p. 146-147, 2007. 
DERANI, C. Direito ambiental econômico. São Paulo: Saraiva, 2008.

EUROPEAN SEA PORTS ORGANISATION - ESPO. Environmental code of pratice. Available at: <http://www.espo.be/> Access on: 16 July 2011.

FENSTERSEIFER, T. Direitos fundamentais e proteção do ambiente: a dimensão ecológica da dignidade humana no marco jurídico-constitucional do estado socioambiental de direito. Porto Alegre: Livraria do Advogado, 2008.

GITAHY, M. L. C. Ventos do mar: trabalhadores do porto, movimento operário e cultura urbana. São Paulo: Editora da Universidade Estadual Paulista, 1992.

MILARÉ, E. Direito do ambiente. 5. ed. São Paulo: Revista dos Tribunais, 2007. MORAES, I. R. O desenvolvimento portuário, integração porto-cidade e a proteção do patrimônio histórico cultural: referências para Santos. In: CONGRESSO INTERNACIONAL DE DIREITO AMBIENTAL, 1., 2007, São Paulo. Anais... São Paulo: Imprensa Oficial do Estado de São Paulo, 2007.

MONTEIRO Jr., J.; VENDRAMETTO, O. O tratamento dado aos resíduos sólidos pela administração do porto de Santos. 2009. Disponível em: <http://www.advencesinclearproduction.net/second/files/sessoes/4b/3/ j.\%Monteiro\%20Junior\%20-\%20resumo\%20exp.pdf >. Acesso em: 25 jun. 2011.

NUSDEO, F. Sustentabilidade. In: MARQUES, J. R. Sustentabilidade e temas fundamentais de direito ambiental. Campinas: Milennium, 2009. p. $145-157$.

OLIVEIRA, U. C. Gerenciamento de água de lastro nos portos. Brasília: ANTAQ, 2008. Disponível em: <http://www.antaq.gov.br/portal/pdf/palestras/ UiraCavalcanteOliveiraCBO08Fortaleza.pdf〉. Acesso em: 24 jun. 2011.

PEREIRA, L.; MAIA, N. M. A.; PEREIRA, W. F. A importância do investimento em pátios reguladores de caminhões nos portos brasileiros. Disponível em: 〈http://www.cbtu.gov.br/estudos/pesquisa/antp_15congr/pdf/TP-055.pdf〉. Acesso em: 2 jul. 2011.

Rev. Direito Econ. Socioambiental, Curitiba, v. 3, n. 2, p. 375-399, jul./dez. 2012 
PRADO, C. País precisa reduzir gargalos até os portos. 2009. Disponível em: <http://www.portogente.com.br/texto.php?cod=23819>. Acesso em: 2 jul. 2011. SILVA, G.; COCCO, G. Cidades e portos. Rio de Janeiro: DP\&A, 1999.

VIEIRA, L. M. Avaliação da qualidade do ar em um porto através de parâmetros físico-químicos e toxicológicos. 2007. 136 f. Dissertação (Mestrado em Ciência e Tecnologia Ambiental) - Universidade do Vale do Itajaí, Itajaí, 2007.

Recebido: 30/07/2011

Received: 07/30/2011

Aprovado: 12/07/2012

Approved: 07/12/2012 